\title{
INSTRUÇÕES AOS AUTORES
}

1. A Revista Internacional Interdisciplinar INTERthesis, publicada pelo Programa de Pós-Graduação Interdisciplinar em Ciências Humanas da UFSC, aceita para avaliação artigos inéditos, concisos e consistentes, preferencialmente com abordagem interdisciplinar, estabelecendo pontes entre disciplinas principalmente em áreas temáticas tais como:

- Condição Humana na Modernidade,

- Estudos de Gênero e

- Sociedade e Meio Ambiente

Serão aceitas contribuições nas seguintes modalidades:

a) Artigo: deve ser original, contribuição de caráter acadêmico e/ou técnicocientífico destinada a divulgar resultados de pesquisa científica, de natureza empírica, experimental ou conceitual (mínimo de 12 e máximo de 18 páginas, incluindo títulos, resumos, tabelas, figuras, mapas e referências).

b) Revisão: avaliação crítica sistematizada da literatura sobre determinado assunto; deve-se citar o objetivo da revisão, especificar (em métodos) os critérios de busca na literatura e o universo pesquisado, discutir os resultados obtidos e sugerir estudos no sentido de preencher lacunas do conhecimento atual (mínimo de 12 e máximo de 18 páginas, incluindo títulos, resumos, tabelas, figuras, mapas e referências).

c) Ensaio: reflexão circunstanciada, com redação adequada ao escopo de uma publicação científica, com maior liberdade por parte do autor para defender determinada posição, que vise aprofundar a discussão ou que apresente nova contribuição/abordagem a respeito de tema relevante (mínimo de 12 e 
máximo de 18 páginas, incluindo títulos, resumos, tabelas, figuras, mapas e referências).

d) Resenha: análise crítica sobre livro publicado nos últimos dois anos (até 6 páginas, com as mesmas configurações que se solicita ao texto, incluindo referência bibliográfica completa no cabeçalho).

2. Artigo submetido por aluno(a) de pós-graduação (Mestrado e/ou Doutorado) somente será aceito se escrito em co-autoria com o(a) Orientador(a), conforme sugere a Coordenação de Aperfeiçoamento de Pessoal de Nível Superior CAPES.

3. Todos os artigos são apreciados por dois avaliadores, através do sistema Blind Review, ou seja, "avaliação cega” e caso necessário será enviado ainda a um terceiro avaliador.

4. Os originais poderão ser:

a) aceito/aprovado para publicação sem restrições;

b) aprovado se cumpridas as modificações sugeridas, sem necessidade de retornar ao parecerista;

c) aprovado se cumpridas as modificações sugeridas, com necessidade de releitura pelo parecerista;

d) parcialmente rejeitado, necessita de ampla revisão e deverá ser reapresentado para nova avaliação/parecer;

e) rejeitado.

5. É de responsabilidade do(s) autor(es) promover(em) as devidas revisões gramaticais no texto encaminhado bem como se preocupar com a obtenção de autorização de direitos autorais com relação ao uso de imagens, figuras, tabelas, métodos etc. junto a outros autores ou editores, quando for o caso. 
6. Texto aceito para publicação que deseje ser traduzido para o inglês sugere-se a correção pelo American Journal Experts (www.journalexperts.com) e deverá ser custeado pelos autores.

7. A INTERthesis reserva-se o direito de evitar a publicação de um mesmo autor em intervalos menores do que quatro edições.

8. O conteúdo dos trabalhos é de responsabilidade exclusiva de seus autores.

9. Quando as alterações forem referentes apenas a aspectos gramaticais, ortográficos e de ordem normativa, com vistas a manter a homogeneidade da publicação, editores e editores assistentes têm o direito de fazer as modificações necessárias, respeitando o estilo do autor. Nos demais casos, o autor reformulará o texto conforme o que for solicitado retornando-o no prazo máximo estipulado pelo editor que poderá ser de até 30 dias para releitura/nova avaliação.

10. Quando for sugerido na "avaliação por pares" revisão gramatical mais acurada do manuscrito poderá ser sugerido aos autores que se responsabilizem pela revisão a ser realizada por um profissional formado em Letras, quando são observadas as normas da Língua Portuguesa culta.

11. Os artigos e demais trabalhos publicados na INTERthesis passam a ser propriedade da revista. A impressão, total ou parcial, fica sujeita à expressa menção da procedência de sua publicação citando-se a edição, data da publicação, endereço eletrônico e data do acesso.

12. Os textos podem ser apresentados em três idiomas português, espanhol ou inglês.

13. Os artigos deverão ser redigidos conforme a norma de apresentação de artigos da Associação Brasileira de Normas Técnicas - ABNT - NBR6022 de maio de 2003.

14. Para os artigos em língua espanhola ou inglesa, os autores deverão utilizar as normas brasileiras, da Associação Brasileira de Normas Técnicas (ABNT), conforme exposto no item anterior. 
15. Anonimato:

a) No texto submetido para avaliação NÃO deve constar o(s) nome(s) do(s) autor(es).

b) Solicita-se ao(s) autor(es) que antes de submeter o texto, retire o(s) nome(s) da autoria ou qualquer identificação do texto ou qualquer identificação do arquivo enviado, inclusive na opção propriedades do "Word".

16. Submissão eletrônica: Os artigos deverão ser remetidos via plataforma em http://www.periodicos.ufsc.br/index.php/interthesis/about/submissions\#onlineSub $\underline{\text { missions }}$

17. O arquivo contendo o manuscrito, que será anexado (transferido), durante a submissão, não poderá ultrapassar o tamanho de $3 \mathrm{MB}$.

18. Se o autor já estiver cadastrado, é necessário somente fazer o Login e iniciar os passos para a submissão do trabalho. Se ainda não estiver cadastrado é necessário usar o link Não está cadastrado? Cadastre-se no sistema http://www.periodicos.ufsc.br/index.php/interthesis/user/register, preencher o formulário e completar as informações.

19. Em seguida, utilize o link Autor e inicie o processo de submissão do artigo. São cinco passos, lembre-se de salvar no final de cada etapa:

Início: escolher em qual seção se encaixa o texto (Artigo, Ensaio ou Resenha) e indicar o idioma do texto;

a) Confirme marcando nas caixas de seleção que a submissão está em conformidade com as condições da revista antes de prosseguir ao $2^{\circ}$ Passo do processo.

b) Transferência do Manuscrito: Transferir o arquivo em .doc ou .docx, lembrando de remover qualquer tipo de identificação de autoria;

c) Inclusão de Metadados: Preencher os dados de autoria, inclusive o resumo de biografia. Caso tenha mais de um autor, clicar em "incluir autor" e preencher 
os dados. Preencher os campos de título e resumo em caixa baixa. Preencher os campos de indexação, palavras-chave é item obrigatório.

d) Transferência de Documentos Suplementares: Etapa opcional. Podem ser anexados documentos como autorizações de publicação e uso de fontes ou complementos ao artigo como tabelas, figuras, gráficos, mapas e fotos inerentes ao texto enviado.

e) Confirmação: confirmação de que o arquivo foi anexado ao sistema e conclusão da submissão.

\section{Características gerais do texto:}

O texto submetido deve ser digitado em Word 2003 (ou superior).

A formatação do texto e das referências deve seguir as especificações abaixo:

\section{1) Formatação do texto}

Como formato e características gerais, o texto deve ser/ter:

a. Digitado em Word;

b. Espaço 1,5 cm;

c. Alinhamento justificado;

d. Letra tipo Arial, corpo 12;

e. Papel em formato A4;

f. Margens superior/inferior - direita/esquerda $=2,5 \mathrm{~cm}$;

g. Parágrafo com recuo na primeira linha $=1,25 \mathrm{~cm}$;

h. Se possível, evite notas de rodapé. Ao utilizá-las, contudo, elas devem vir ao final da página, em numeração contínua, fonte Arial, tamanho 10, espaçamento simples, alinhamento justificado.

2) O manuscrito deve ser elaborado nesta sequência: 


\section{Elementos pré-textuais (1ª́ página):}

a. Título e subtítulo (se houver) na língua do texto;

I. No cabeçalho deve ficar em alinhamento justificado, em letras maiúsculas, negrito, fonte Arial 12, espaçamento entre linhas simples e ter no máximo 15 palavras.

b. Resumo na língua do texto;

I. Resumo deve ter no mínimo 100 e no máximo 250 palavras, expondo a abordagem principal do texto.

II. Deve ser claro e conciso, num único parágrafo, ficar em alinhamento justificado, fonte Arial 12, espaçamento entre linhas simples contendo o objetivo, metodologia, resultados e conclusões, seguindo a norma da ABNT NBR6028/2003;

c. Palavras-chave na língua do texto.

I. Devem ser apresentadas, 05 (cinco) palavras-chave que melhor representem o assunto do artigo. As palavras devem ser separadas por ponto, conforme exemplo:

Palavras-chave: Uma palavra. Duas. Três. Quatro. Cinco palavras.

\section{Elementos textuais (Corpo do texto do artigo)}

a. O manuscrito deve ser apresentado em espaçamento 1,5, justificado, fonte Arial 12, e parágrafo com recuo na primeira linha de $1,25 \mathrm{~cm}$.

b. Sugere-se que o texto obedeça à seguinte sequência: Introdução, Metodologia ou Procedimentos metodológicos/operacionais, Capítulos ou subdivisões do corpo do trabalho, Considerações Finais ou Conclusões, e Referências. Títulos das seções em caixa alta, negrito.

Tabelas, figuras, gráficos e mapas

a. Qualquer tipo de ilustração apresentada deve ser inserida no texto, o 
mais próximo possível do trecho a que se pretende ilustrar, evitando expressões como "Figura a seguir" ou "tabela abaixo" e utilizando sempre a numeração: Conforme tabela 5. De acordo com o gráfico 10.

b. O tamanho das ilustrações não deve exceder as margens.

c. As tabelas com informações estatísticas devem seguir as normas de apresentação tabular do IBGE/1993. Define-se tabela, a forma não discursiva de apresentar informações, na qual se destacam os números e informações estatísticas.

d. A identificação de uma tabela deve ser feita através de números arábicos precedidos da palavra Tabela e seguidos de seu título. Essa identificação deverá aparecer acima da referida tabela.

e. A tabela não é fechada com traços nos lados direito e esquerdo, ou seja, não há delimitação lateral. Recomenda-se que as tabelas presentes no artigo possuam uniformidade gráfica, quanto a cores e layout, utilizando fonte Arial 10 no máximo para os dados apresentados, ou, no caso de fonte externa, pode ser apresentada como imagem JPEG. A fonte deve ser indicada abaixo da mesma, conforme exemplo a seguir:

\begin{tabular}{|c|c|c|c|c|}
\hline & $\begin{array}{l}\text { Situaçáo } \\
\text { do } \\
\text { domicilio }\end{array}$ & Total & Mulheres & Homens \\
\hline Total & & 117960301 & 59595332 & 58364969 \\
\hline Urbana & & 79972931 & 41115439 & 38857492 \\
\hline Rural & & 37987370 & 18479893 & 19507477 \\
\hline
\end{tabular}

Fonte: Fundaçåo Instituto Brasileiro de Geografia e Estatistica - IBGE.

f. As demais ilustrações, como desenhos, mapas, organogramas, 
fotografias e outras, devem ser inseridas no texto em formato JPEG e enviadas também em documentos suplementares independentes, através do sistema online da revista, no mesmo formato. A identificação aparece na parte inferior da imagem, com a numeração de ordem sendo a mesma identificada no texto. A fonte deve vir em seguida. A formatação da legenda deve ser em fonte Arial tamanho 10 , negrito.

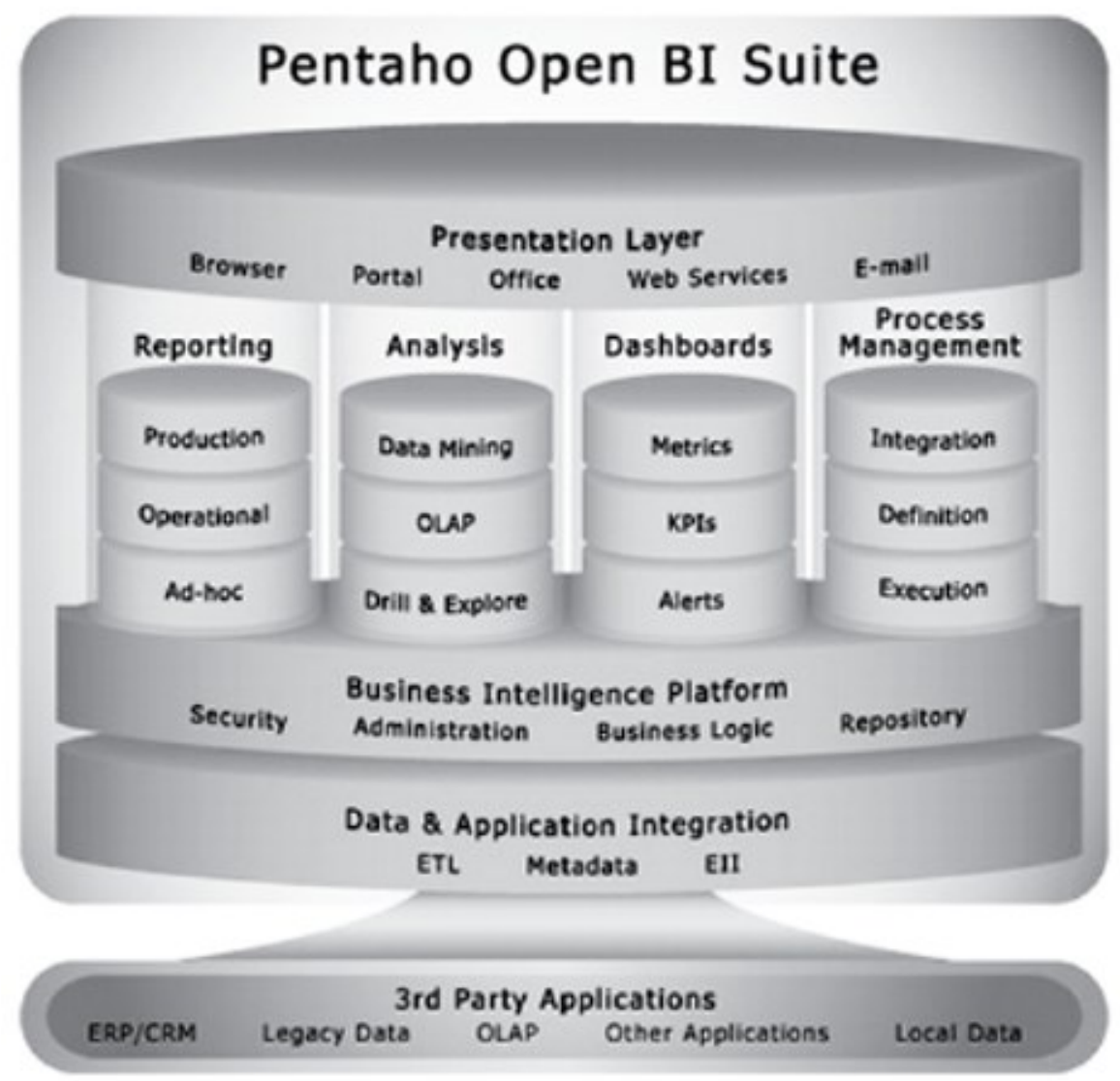

Figura 1 - Componentes da Suite.

Fonte: Tessler e Sales (2008) 


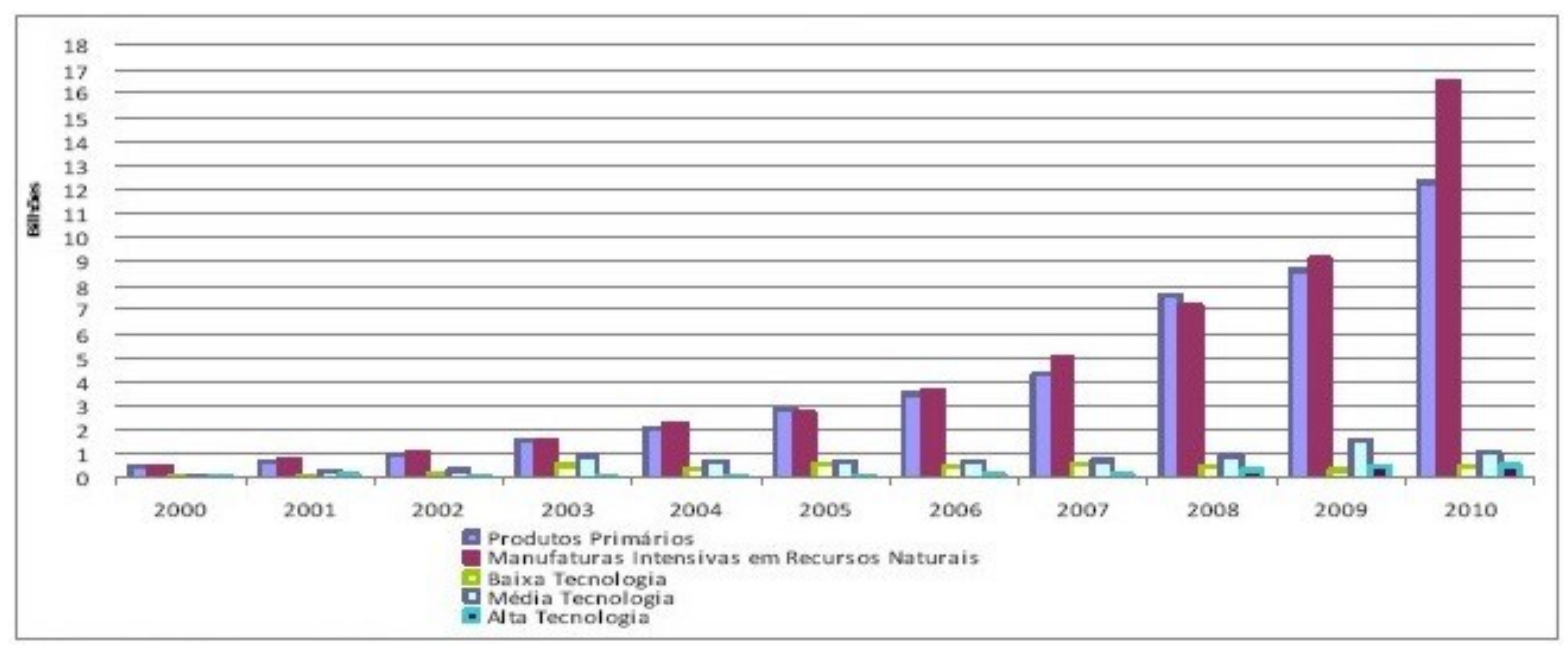

Gráfico 5 - Pauta exportadora do Brasil com a China, por intensidade tecnológica do produto.

Fonte: UNContrade.

g. As fontes utilizadas para quaisquer tipos de ilustração, exceto quando for elaboração do próprio autor, deverão ser referenciadas ao final do artigo.

\section{Citações}

a. As citações diretas com até três linhas devem estar entre aspas duplas, no corpo do texto. As citações devem ser elaboradas de acordo com a norma da ABNT NBR10520/2002, usando obrigatoriamente o sistema autor-data.

\section{Exemplos:}

Carvalho e Schmitz (1990, p.149) afirmam que "até os anos 70 os princípios do fordismo guiaram internacionalmente a administração na indústria automobilística e em outras indústrias de produção em massa".

$\mathrm{Ou}$

"Até os anos 70 os princípios do fordismo guiaram internacionalmente a administração na indústria automobilística e em outras indústrias de produção em massa" (CARVALHO; SCHMITZ, 1990, p.149). 
b. As citações diretas com mais de três linhas (citação longa) devem ser destacadas:

I. com recuo de $\mathbf{4} \mathbf{c m}$ da margem esquerda;

II. em fonte 10;

III. espaçamento simples;

IV. pôr espaçamento antes e depois de 12 pt;

V. sem aspas;

VI. em caso de supressão de texto, utilizar [...]

Exemplo:

São abundantes os sinais e marcas de modificações radicais em processos de trabalho, hábitos de consumo, configurações geográficas e geopolíticas, poderes e práticas do Estado etc. [...] ainda vivemos uma sociedade em que a produção em função de lucros permanece como princípio organizador básico da vida econômica. Portanto, precisamos de alguma maneira representar todos os grandes eventos ocorridos desde a primeira grande recessão do pós-guerra, em 1973, maneira que não perca de vista o fato de as regras básicas do modo capitalista de produção continuarem a operar como forças plasmadoras invariantes do desenvol vimento históricogeográfico (HARVEY, 2002, p.117).

\section{Elementos pós-textuais:}

\section{(após término do corpo do manuscrito, antes das Referências):}

a. Títulos e subtítulos (se houver) em línguas estrangeiras (inglês e espanhol).

b. Resumos em línguas estrangeiras (inglês e espanhol).

i. Abstract e Resumen, em alinhamento justificado, fonte Arial 12, espaçamento entre linhas simples.

c. Palavras-chave em línguas estrangeiras (inglês e espanhol). 
i. Keywords e Palabras clave, em alinhamento justificado, fonte Arial 12, espaçamento entre linhas simples, devem ser separadas por ponto e iniciadas com letra maiúscula.

\section{Referências}

a) No item das "Referências" somente devem constar os textos, artigos e documentos que foram utilizados no corpo do texto. Utilizar a norma NBR 6023/2002 para a elaboração das referências.

b) Quanto ao primeiro nome do autor, deve-se optar por escrevê-lo ou por extenso ou utilizando-se somente a inicial do primeiro nome, devendo-se seguir um só modo para todas as obras referenciadas.

c) A revista recomenda que vinte por cento $(20 \%)$ das referências bibliográficas e/ou citações sejam de artigos que façam parte de bases internacionais como, por exemplo: SciELO, Scopus ou ISI Web of Knowledge, com menos de 10 anos.

d) Solicita-se evitar no artigo a autocitação, citação de monografias, anais, resumos, resumos expandidos, jornais e magazines.

e) Para um mesmo autor referenciado em sequência, deve-se repetir seu nome, não utilizando sublinhados.

f) As referências são alinhadas somente a margem esquerda do texto e de forma a se identificar individualmente cada documento, em espaço simples e separadas entre si por espaço duplo. Devem ser apresentadas em ordem alfabética.

\section{Livro}

\section{Quando há apenas um autor:}

FACHIN, Odília. Fundamentos de metodologia. 4. ed. São Paulo: Saraiva, 2003. SCHÜTZ, Edgar. Reengenharia mental: reeducação de hábitos e programação de metas. Florianópolis: Insular, 1997.

\section{Quando houver dois ou três autores:}


LAKATOS, E. M.; MARCONI, M. de A. Metodologia científica. 2. ed. São Paulo: Atlas, 1991.

CASTILLO, G.; KOSTOF, S.; TOBIAS, R. A history of architecture: settings and rituals. Oxford: Oxford University Press, 1995.

Quando houver mais de três autores:

CAJUEIRO, Daniel Oliveira et al. Modelo de localização industrial para o planejamento de um pólo de alta tecnologia. Brasília: IPEA, 2005. 18p. (Texto para discussão, 1.134).

MAGAlHÃES, A. D. F. et al. Perícia contábil. 3. ed. São Paulo: Atlas, 2001.

BRITO, E. V. et al. Imposto de renda das pessoas físicas: livro prático de consulta diária. São Paulo: Frase Editora, 1996.

Quando houver organizador (Org.), coordenador (Coord.) ou editor (Ed.):

BOSI, A. (Org.). O conto brasileiro contemporâneo. 6. ed. São Paulo: Cultrix, 1989.

VERSIANI, Flávio Rabelo; BARROS, José Roberto Mendonça de (Org.). Formação econômica do Brasil: a experiência da industrialização. São Paulo: Saraiva, 1978.

Quando não há local de publicação:

KRIEGER, Gustavo; NOVAES, Luís Antonio; FARIA, Tales. Todos os sócios do presidente. 3. ed. [S.I.]: Scritta, 1992. 195 p.

Quando não há o nome da editora:

VALÊNCIA, I. Das mulheres e das flores. Belo Horizonte: [s.n.], 1974.

Quando não há data da edição: sempre deve ser indicada uma data, seja de publicação, de distribuição, do copyright, de impressão ou outra. Se nenhuma data puder ser determinada, coloca-se uma data aproximada entre colchetes [ ], como segue:

[1971] data certa, mas não indicada no material

[1989?] data provável da publicação

[ca1965] data aproximada da publicação

Quando o autor for uma entidade: 
BRASIL. Ministério da Educação. Secretaria de Administração Geral. A educação no Brasil na década de 80. Brasília: MEC, 1990. 106 p.

ASSOCIAÇÃO BRASILEIRA DE NORMAS TÉCNICAS. NBR 6023: Informação e documentação. Rio de Janeiro: ABNT, 2000. 3 p.

PREFEITURA MUNICIPAL DE CASCAVEL Recuperação ambiental da bacia hidrográfica do Rio Cascavel. Cascavel: FUNDETEC. 1995. 164 p.

\section{Quando a obra tiver título e subtítulo:}

CERTEAU, M. de. Histoire et psychanalyse: entre science et fiction. Paris: Gallimard, 1987.

\section{Autoria desconhecida:}

Quando não existe nome de autor, a primeira palavra significativa do título é escrita em caixa alta. Não se usa o termo "anônimo". Exemplo:

O PENSAMENTO vivo de Nietzsche. São Paulo: Martin Claret, 1991. 110p.

\section{Capítulo de livro}

MOURA, Rosa. Políticas públicas urbanas: ausências e impactos. In: MENDONÇA, Francisco (Org.). Impactos socioambientais urbanos. Curitiba: Ed. UFPR, 2004. p.149-168.

PINHEIRO, Armando Castelar; GIAMBIAGI, Fabio; GOSTKORZEWICZ, Joana. O desempenho macroeconômico do Brasil nos anos 90. In: GIAMBIAGI, Fabio; MOREIRA, Maurício Mesquita (Org.). A economia brasileira nos anos 90. Rio de Janeiro: BNDES, 1999. p.11-41.

LIMA, L. de O. Ativação dos processos didáticos na escola secundária. In: LIMA, L. A escola secundária moderna: organização, métodos e processos. Rio de Janeiro: Forense-Universitária, 1976. cap. 12, p. 213-234.

HORTA, J. S. B. Planejamento educacional. In: MENDES, Dumerval Trigueiro (Org.). Filosofia da Educação Brasileira. Rio de Janeiro: Civilização Brasileira, 1991. p.195-239.

\section{Artigo em periódico}

TORRES, Haroldo da Gama et al. Pobreza e espaço: padrões de segregação em São Paulo. Estudos Avançados, São Paulo, v. 17, n. 47, p. 97-128, jan./abr. 2003.

ARAÚJO, S. M. P. Indústria automobilística e sindicato: atuação renovada no Paraná dos anos 2000. Cadernos do CRH, Salvador, v. 19, n. 46, p. 49-62, 2006. 
SCHNEIDER, Sergio; BLUME, Roni. Ensaio para uma abordagem territorial da ruralidade: em busca de uma metodologia. Revista Paranaense de

Desenvolvimento, Curitiba, n. 197, p. 109-135, jul./dez. 2004.

AZZONI, Carlos R.; CARMO, Heron E. do; MENEZES, Tatiane. Comparações da paridade de poder de compra entre cidades: aspectos metodológicos e aplicação ao caso brasileiro. Pesquisa e Planejamento Econômico, Rio de Janeiro, v. 33, n. 1, p. 91-126, abr. 2003.

\section{Dissertação e Tese}

\section{Dissertação de Mestrado:}

RODRIGUES, M. V. Qualidade de vida no trabalho. 1989. 180 f. Dissertação (Mestrado em Administração) - Faculdade de Ciências Econômicas, Universidade Federal de Minas Gerais, Belo Horizonte, 1989.

Tese de doutorado:

DELGADO, Paulo Roberto. Precarização do trabalho e condições de vida: a situação da Região Metropolitana de Curitiba nos anos 90. 2001. 163 f. Tese (Doutorado) - Universidade Federal do Paraná, Curitiba, 2001.

FANTUCCI, I. Contribuição do alerta, da atenção, da intenção e da expectativa temporal para o desempenho de humanos em tarefas de tempo de reação. 2001. 130 f. Tese (Doutorado em Psicologia) - Instituto de Psicologia, Universidade de São Paulo, São Paulo, 2001.

\section{Acesso via Internet}

\section{Artigo de Internet com autor:}

MOULIN, Carolina. Os direitos humanos dos humanos sem direitos: refugiados e a política do protesto. Rev. bras. Ci. Soc., São Paulo, v. 26, n. 76, jun. 2011. Disponível em: <http://www.scielo.br/scielo.php?script=sci_arttext\&pid=S010269092011000200008\&lng=pt\&nrm=iso>. Acesso em: 16 dez. 2011. http://dx.doi.org/10.1590/S0102-69092011000200008.

CAPITANI, Daniel Henrique Dario; MIRANDA, Sílvia Helena Galvão de; FILHO, João Gomes Martines. Determinantes da demanda brasileira por importação de arroz do Mercosul. Rev. Econ. Sociol. Rural, Brasília, v. 49, n. 3, set. 2011 . Disponível em: <http://www.scielo.br/scielo.php?script=sci_arttext\&pid=S010320032011000300002\&lng=pt\&nrm=iso>. Acesso em: 27 dez. 2011. http://dx.doi.org/10.1590/S0103-20032011000300002.

SCAFFO, Maria Fátima; FARIAS, Francisco Ramos. A transmissão dos protocolos de gênero como dispositivo de submissão feminina à violência conjugal.

INTERthesis, Florianópolis, v. 8, n. 2, p. 134-159, Jul./Dez. 2011 Disponível em: <http://www.periodicos.ufsc.br/index.php/interthesis/article/view/1807- 
1384.2011v8n2p134/20572 > Acesso em: 28 dez. 2011. DOI:10.5007/1807$1384.2011 \mathrm{v} 8 \mathrm{n} 2 \mathrm{p} 134$

MONT'ALVAO, Arnaldo. Estratificação educacional no Brasil do século XXI. Dados, Rio de Janeiro, v. 54, n. 2, 2011 . Disponível em:

$<$ http://www.scielo.br/scielo.php?script=sci_arttext\&pid=S0011-

$52582011000200006 \&$ Ing=pt\&nrm=iso>. Acesso em: 28 dez. 2011.

http://dx.doi.org/10.1590/S0011-52582011000200006.

COSTA. M. Agronegócio: o motor da economia brasileira e o dinamismo da economia paranaense. Agronline.com.br. Disponível em:

<http://www.agronline.com.br/ artigos/artigo.php?id=331>. Acesso em: 10 mar. 2011.

BARBOSA, Lucia Martins et al. A representação social do professor sob o ponto de vista do aluno. Revista Aprender Virtual, Marília, dez. 2003. Disponível em: $<$ http://www.aprendervirtual.com/ver_noticia.php?codigo=32 > . Acesso em: 02 fev. 2004.

\title{
Artigo de Internet sem autor especial:
}

CIÊNCIA DA INFORMAÇÃO. Brasília, v.26. n.3, 1997. Disponível em: <http://www.ibict.br/cionline >. Acesso em: 19 mai. 1998.

\section{Verbete de dicionário}

ÉTICA. In: FUNDAÇÃO GETÚLIO VARGAS. Instituto de documentação. Dicionário de ciências sociais. Rio de Janeiro: FGV, 1986. p. 433-435.

\author{
Universidade Federal de Santa Catarina - UFSC \\ Centro de Filosofia e Ciências Humanas - CFH \\ Programa de Pós-Graduação Interdisciplinar em Ciências Humanas - PPGICH
}

\section{Editores:}

Selvino Assmann, Silmara Cimbalista e Javier Vernal

http://www.periodicos.ufsc.br/index.php/interthesis/index

E-mail: interthesis@gmail.com 